\title{
RADIOLOGICAL IMAGES
}

\section{COVID-19 Pneumonia: Bilateral Peripheral Consolidations with Basal Predominance}

Images from different patients with COVID-19 pneumonia showing characteristic X-ray findings of this disease
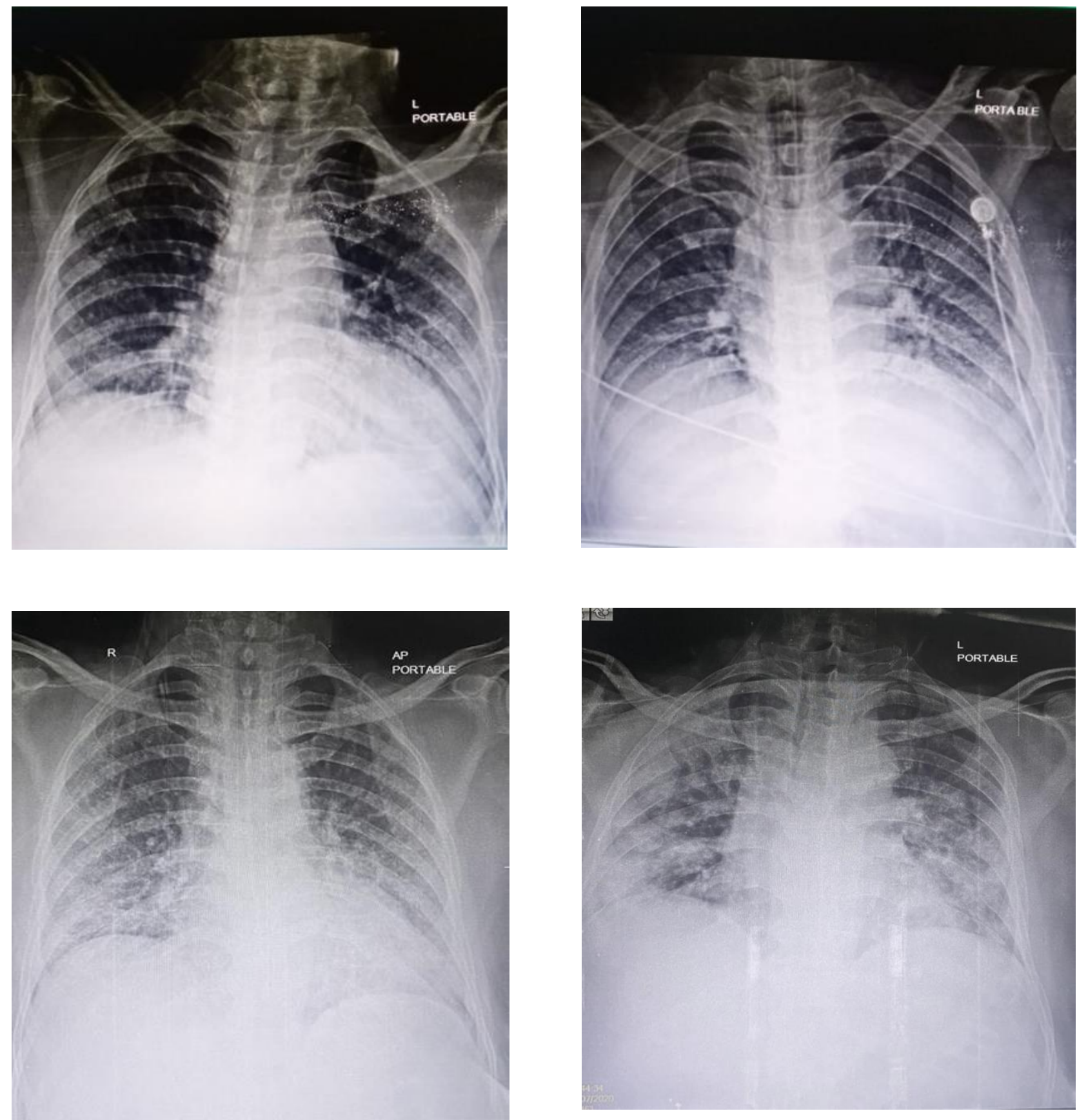

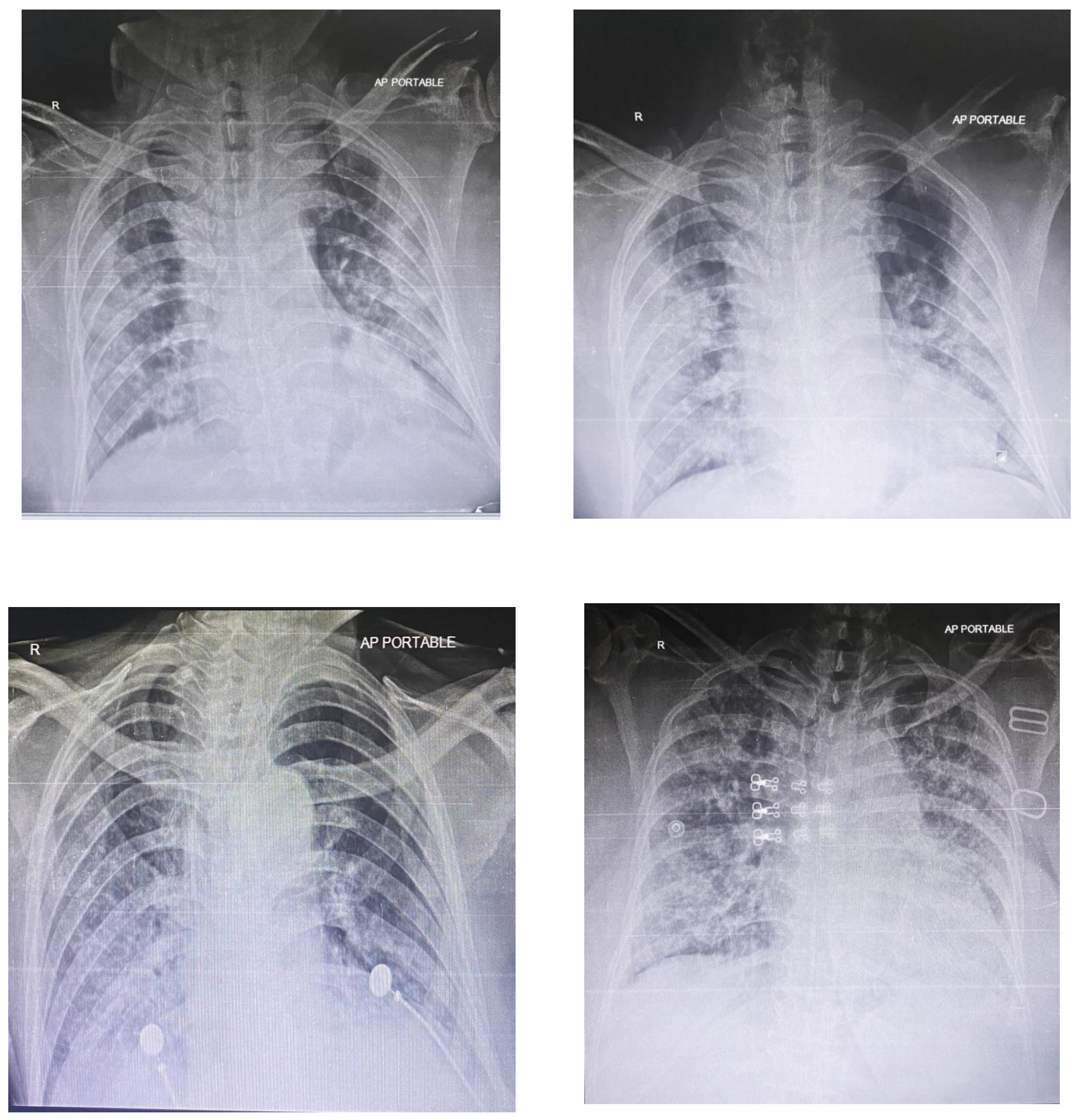

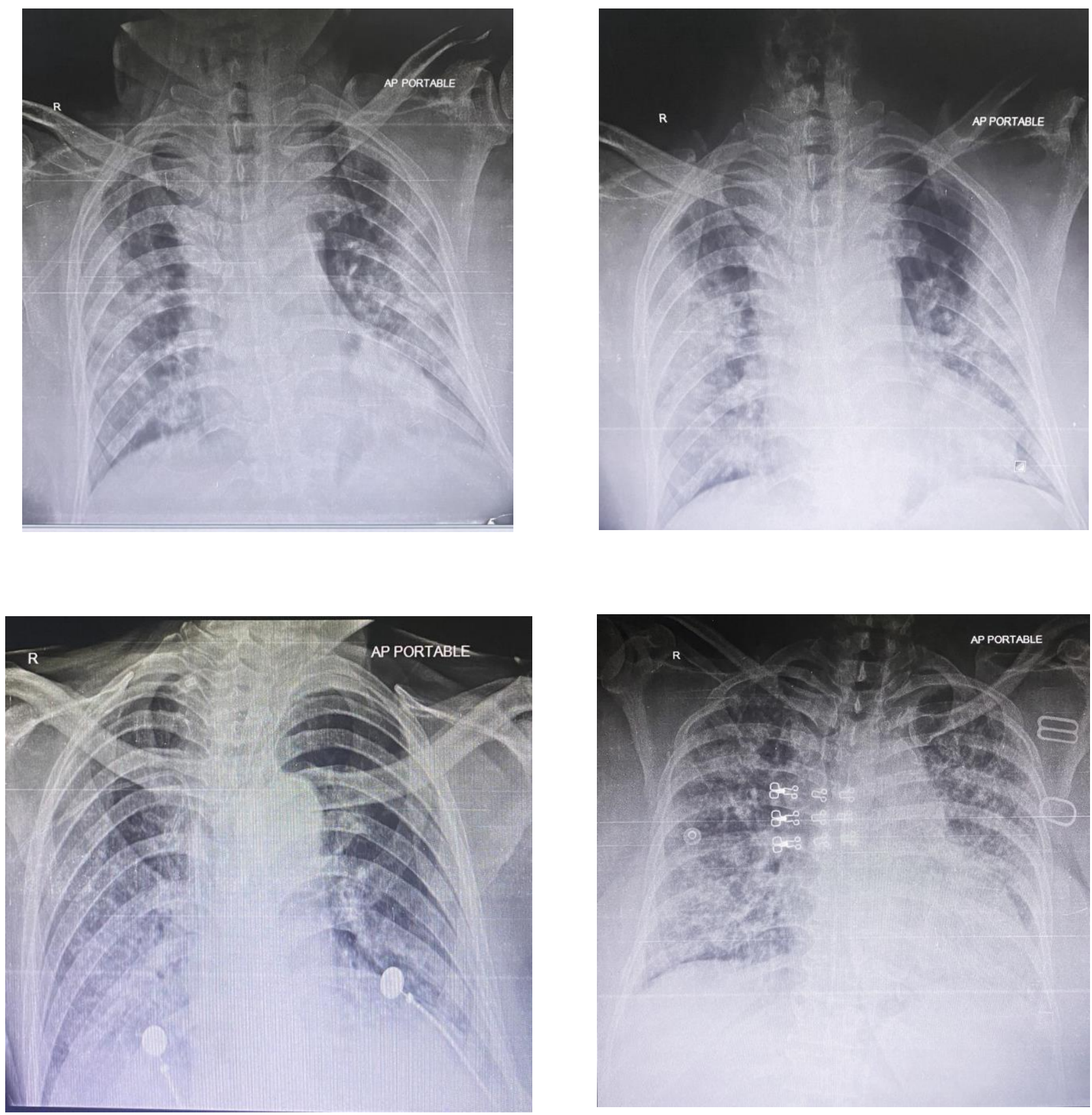

\section{Contributed by:}

Department of Radiology

Dr. Akbar Niazi Teaching Hospital, Islamabad 